\title{
Abstracts of the European Association for Potato Research Pathology Section Meeting 2010 on: Potato Pests and Diseases: Old Enemies, New Threats held at Carlow, Ireland, 13th-16th September 2010
}

(C) The Author(s) 2010. This article is published with open access at Springerlink.com

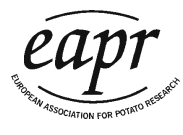

Edited by: Louise Cooke (Email: Louise.Cooke@afbini.gov.uk)

Potato Genome Sequencing and its Potential for Resistance Breeding in Potato

D. Milbourne

Teagasc Crops Research Centre, Oak Park, Carlow, Ireland

E-mail: Dan.Milbourne@teagasc.ie

Potato is the world's most important vegetable crop and a key member of the Solanaceae. The $840 \mathrm{Mb}$ genome of potato has recently been sequenced by the global Potato Genome Sequencing Consortium (PGSC). Initially the sequencing effort employed a chromosome by chromosome, BAC by BAC sequencing strategy of the diploid potato genotype "RH89-039-16". More recently, a doubled monoploid clone "DM1-3 516R44" has been used to develop a high quality draft sequence using Next Generation Sequencing. The consortium members are currently generating annotation of the genes, examining the transcriptome of potato in different tissues and developmental stages, in response to a variety of biotic and abiotic stresses, and performing more indepth analyses of genes critical to potato biology. The timely release of the potato genome sequence provides the entire Solanaceae research community an opportunity to exploit the genome sequence for fundamental and applied biological studies. This presentation will provide an overview of the current state of the genome sequence and the potential for exploiting this sequence to examine the molecular basis for resistance against a wide variety of pests and diseases, and for breeding disease resistant varieties.

\section{Assisting in the Fight Against Phytophthora infestans: Gene Transfer into Solanum tuberosum via Rhizobium spp.}

\section{E. Mullins}

Teagasc Crops Research Centre, Carlow, Ireland

E-mail: ewen.mullins@teagasc.ie

Genetic transformation is a powerful research tool for gene discovery and function, particularly in response to biotic stress. Agrobacterium tumefaciens-mediated 
transformation (ATMT) is the preferred technique for gene transfer into crops but a major disadvantage of ATMT remains the complexity of the patent landscape which restricts its use for commercial applications. An alternative system has been described (Broothaerts et al. in Nature 433:629-633, 2005) detailing the propensity of three rhizobia to transform the model crop Arabidopsis thaliana, Nicotiana tabacum and, at a very low frequency, Oryza sativa. In this report we describe for the first time the genetic transformation of Solanum tuberosum using the nonAgrobacterium species Sinorhizobium meliloti, Rhizobium sp. NGR234 and Mesorhizobium loti. This was achieved by combining an optimal bacterium and host co-cultivation period with a low antibiotic regime during the callus and shoot induction stages. Using this optimized protocol the transformation frequency (calculated as $\%$ of shoots equipped with root systems with the ability to grow in rooting media supplemented with $25 \mu \mathrm{g} / \mathrm{ml}$ hygromycin) of the strains of rhizobia was calculated at $4.72,5.85$ and $1.86 \%$ for $S$. meliloti, $R$. sp. NGR234 and M. loti respectively, compared to $47.6 \%$ for the A. tumefaciens control. Stable transgene integration and expression was confirmed via southern hybridisation, quantitative PCR analysis and histochemical screening of both leaf and/or tuber tissue. In light of the rapid advances in potato genomics, combined with the sequencing of the potato genome, the ability of alternative bacteria species to genetically transform this major food crop will provide a novel resource to the Solanaceae community as it continues to develop potato as both a food and non-food crop.

\title{
The Changing Potato Blight Population in Ireland
}

\author{
S. Kildea ${ }^{1}$, L.R. Cooke ${ }^{2}$, L. Quinn ${ }^{2}$, G. Little ${ }^{2}$ C. Armstrong ${ }^{2}$, F. Hutton ${ }^{1}$, and D. \\ Griffin $^{1}$ \\ ${ }^{1}$ Teagasc Crops Research Centre, Oak Park, Carlow, Ireland \\ ${ }^{2}$ Agri-Food and Biosciences Institute (AFBI), Northern Ireland, UK \\ E-mail: Stephen.Kildea@teagasc.ie
}

Phytophthora infestans, the causal agent of late blight, is still the single biggest disease threat to potato production in Ireland. Disease control programmes, whether using host resistance or fungicides, are compromised by the capacity of $P$. infestans to evolve and adapt. The introduction of the $P$. infestans A2 mating type into Europe in the mid 1970s enhanced this capability. The A2 mating type was first identified in Northern Ireland in 1987 and in the Republic of Ireland the following year. After limited detection in the mid 1990s, it was not detected again in the Irish population until 2005, when it was detected in Northern Ireland. Its increased detection in Northern Ireland in 2007 (17\% of extensive sampling) and the identification of genotype 13_A2 (commonly referred to as 'Blue 13') initiated an all-island study into the Irish P. infestans population. In 2008, this study showed the presence of 13_A2 within the Republic of Ireland, with this strain accounting for $25 \%$ of isolates from the overall Irish population. The presence of the A1 genotype 6_A1 ('Pink 6') was also confirmed in the Irish population in 2008, albeit at an extremely low frequency (1\%). During the 2009 season, the frequency of both 13_A2 and 6_A1 increased, with $>50 \%$ of isolates from the Irish $P$. infestans population being $13_{-}$A2. As Irish potato production is dominated by a limited number of varieties and is reliant on intensive fungicide application, characterisation of the 
aggressiveness of these strains and determination of their sensitivity to the principal blight fungicides are ongoing.

\title{
Aggressiveness of Newly Emerging Isolates of Phytophthora infestans in Ireland
}

\author{
M.W. Nyongesa ${ }^{1,2}$, D.S. Shaw ${ }^{3}$, D. Wright ${ }^{2}$, S. Kildea ${ }^{1}$, D. Griffin ${ }^{1}$, L.R. Cooke ${ }^{4}$ \\ and E. Mullins ${ }^{1}$ \\ ${ }^{1}$ Teagasc Crops Research Centre, Oak Park, Carlow, Ireland \\ ${ }^{2}$ Bangor University, $U K$ \\ ${ }^{3}$ Sárvári Research Trust, Henfaes, UK \\ ${ }^{4}$ Agri-Food and Biosciences Institute (AFBI), Northern Ireland, UK \\ E-mail: ewen.mullins@teagasc.ie
}

The A2 mating type was reported in field populations of Phytophthora infestans in Ireland in the late 1980 s, but this was followed by a steady decline of this mating type in the Irish populations until only A1 types were detected through the early 2000s. In 2007, A2 genotypes were detected once again and their incidence has steadily increased within the Irish population since then. Critically, it is important that we know how aggressive these new genotypes of $P$. infestans are against existing potato germplasm. Thirty isolates of $P$. infestans representing various genotypes (6_A1, 8_A1, 13_A2, 5_A1; according to SSR profiling of polymorphic loci) were assessed for aggressiveness on potato cultivars (9 detached leaflets/isolate/ cultivar) with different levels of susceptibility (cvs Rooster, British Queen) or resistance (cvs Sárpo Mira, Bionica) to late blight. Isolate aggressiveness was assessed based on infection efficiency (IE), latent period (LP), Area Under Lesion Progress Curve (AULPC) and sporulation intensity on each of the four varieties. Significant differences $(P \leq 0.001)$ were observed between isolates in their aggressiveness on the four potato varieties. Although isolates belonging to the 6_A1 and 13_A2 genotypes were significantly $(P \leq 0.001)$ more aggressive than those belonging to 8 A 1 and 5 A1, individual aggressive isolates were found within each genotype. Cultivars also differed significantly in their resistance to disease progress. The disease progress of isolates from all pathogen genotypes studied was significantly $(P \leq 0.001)$ slower on cvs Bionica and Sárpo Mira than on cvs Rooster and British Queen. Isolates with 6_A1 and 13_A2 genotypes had significantly $(P \leq$ $0.001)$ shorter latent periods than those with 8_A1 and 5_A1 genotypes on cvs British Queen and Rooster and caused lesions which produced viable spores on all potato cultivars including Bionica.

\section{Recent Changes in Nordic Potato Diseases and Pathogens}

\author{
A.O. Hannukkala \\ MTT Agrifood Research Finland, Plant Production Research, Finland \\ E-mail: asko.hannukkala@mtt.fi
}

Most of the severe potato diseases have been imported into Nordic Countries via contaminated seed in the late $1800 \mathrm{~s}$ and the early $1900 \mathrm{~s}$. Thereafter the 
epidemiology and population structure of several old pathogens has changed and a few new pathogens have been introduced. Formerly widespread quarantine diseases like potato wart (Synchytrium endobioticum) have been almost fully eradicated. During the later part of the 1990s potato late blight (Phytophthora infestans) became a novel disease. Both mating types, A1 and A2, had established in potato fields during the $1980 \mathrm{~s}$, but since 1998 their proportion in population has been close to $50 \%: 50 \%$. Oospores can be formed in most potato fields where late blight occurs. Severe attacks on emerging potato are common. In Finland onset of late blight epidemics has become 4-5 weeks earlier compared to the 1980s resulting in markedly increased need for fungicide applications. Blackleg and soft rot have been traditionally caused by bacteria in the genus Pectobacterium. In 2003 new blackleg bacteria belonging to the genus Dickeya were detected in Finnish potato fields. During the later part of the 2000s these bacteria rapidly spread throughout potato production. There are at least two different Dickeya species on potato that are more aggressive than Pectobacterium spp. Certain Dickeya strains have caused crop losses up to $50 \%$ in field trials. The management of Dickeya blackleg is complicated compared to Pectobacterium spp. They have a wide host range and capability to survive in soil and natural environments.

\title{
Characterization of Phytophthora infestans Populations in North America from the 2009 Late Bight Epidemic
}

\author{
K.L. Deahl ${ }^{1}$, F.G. Perez ${ }^{1}$, P. Roberts ${ }^{2}$, and J.B. Ristaino ${ }^{3}$ \\ ${ }^{1}$ USDA-ARS/PSI- Genetic Improvement of Fruits and Vegetables Laboratory, \\ Beltsville, MD, USA \\ ${ }^{2}$ Department Plant Pathology, University of FL, USA \\ ${ }^{3}$ Department of Plant Pathology, NC State University, Raleigh, NC, USA \\ E-mail: ken.deahl@ars.usda.gov
}

Phytophthora infestans, the causal agent of potato and tomato late blight, has become a re-emerging disease in the US. In 2009, late blight epidemics were widespread due to inoculum distribution and conducive weather. More than 80 isolates collected from 11 eastern states and Canada in 2009 were genotyped using RFLP, allozyme and SSR markers. The US-8 genotype was found in potato crops in five different states. In addition, three new genotypes, US-22, US-23 and US-24, were found on potato. US-22 (A2; Gpi: 100/122) was widespread on tomato transplants sold to the home garden centres and later thought to have spread to nearby commercial tomato or potato fields. US-23 (A1; Gpi: 100/100) was found in four states on both tomato and potato. US-24 (A1; Gpi: 100/100/111) was found only in North Dakota on potato. Both mating types occurred in the same fields in PA. The severe late blight epidemics of 2009 document the need for an improved web-based database for tracking and monitoring this important plant pathogen on both potato and tomato. Understanding variation in pathogen populations of $P$. infestans is clearly a significant factor in the planning of effective and durable control strategies but $P$. infestans populations have been in a state of flux, and late blight management remains a significant challenge to the industry. 


\title{
Impact of Changes in GB Late Blight Population on the Resistance of Potato Cultivars to Foliar Late Blight
}

\author{
S.F. Carnegie ${ }^{1}$, A.K. Lees ${ }^{2}$ and A.M.I. Roberts ${ }^{3}$ \\ ${ }^{1}$ SASA, Edinburgh, Scotland \\ ${ }^{2}$ SCRI, Dundee, Scotland \\ ${ }^{3}$ Biomathematics \& Statistics Scotland, Edinburgh, Scotland \\ E-mail: stuart.carnegie@sasa.gsi.gov.uk
}

New potato cultivars entered for National List registration in the United Kingdom are tested by SASA for susceptibility to foliar late blight by inoculating glasshouse-grown test plants. Since 2004, SASA has also undertaken late blight testing in the field for the Potato Council Ltd (PCL) at a site shared with SCRI in the west of Scotland where conditions are generally favourable for the natural development of the disease. Both of these tests are conducted using an isolate which is virulent to as many $R$-genes as possible. Changes in the genotypes occurring in the late blight populations between 2006 and 2007 resulted in a more aggressive genotype, 13_A2, replacing the old clonal A1 type. This new genotype now comprises $c .80 \%$ of the population. Since 2008 , variety testing has been conducted with an isolate of 13_A2 genotype, replacing a 5_A1 isolate collected from cv. Sárpo Mira in Wales in 2001. A programme to evaluate the resistance of over 50 existing cultivars to the new genotype over 2 years is being funded by PCL and through a Defra Link project. This has already revealed significant shifts in the rating of many cultivars previously rated as having a degree of resistance (5 or more), e.g. cvs Stirling, Galactica, rated as much more susceptible and has identified varieties, both new, e.g. cv. Sárpo Mira, and older, e.g. cvs Roslin Eburu, Black Castle, as having a good degree of resistance to the 13_A2 genotype. This testing is part of a co-ordinated programme to evaluate the resistance of existing potato cultivars to 13 A2 genotype over 2 years of testing with the aim of eventually publishing statistically calculated ratings on The British Potato Variety Database (www.potato.org).

\section{Response of Sárpo and Other Varieties of Potato to New Strains of Late Blight, Phytophthora infestans}

\section{D.S. Shaw and S. White}

Sárvári Research Trust, Henfaes Research Centre, Abergwyngregyn, Llanfairfechan, LL33 OLB, UK

E-mail: shaw@sarvari-trust.org

The Sárvári Research Trust, set up in North Wales in 2002, has screened clones bred by the Sárvári family in Hungary for resistance to late-blight disease and has compared these with commercially available varieties known to express some resistance. Clones have also been assessed for commercial potential. Annual field trials have been conducted in NW Wales and several other sites conducive to lateblight disease.

In 2005, we detected a new strain (Blue) characterised by multi-locus probe RG57 and mating type A2 in a mapping project funded by The Potato Council Ltd. 
The distinctness of this strain was confirmed by SCRI using SSR markers (genotype 13). This Blue 13 strain has spread rapidly over the UK and is now by far the commonest strain. More recently, another new strain, Pink 6, of A1 mating type has increased in frequency in U.K.

Results of field trials of Nationally Listed Sárpo varieties, other promising Sárpo clones and other commercial varieties are presented and show that resistance in some varieties is eroded while that of most Sárpo varieties and clones is durable. We predict that Sárpo varieties have a future for low-input and organic growing due not only to blight and virus resistance, but also to weed smothering ability and long dormancy.

\title{
Evaluation of Late Blight Control in Potato Cultivars for Reduced Input Production in Northern Ireland
}

\author{
L.R. Cooke and G. Little
}

Applied Plant Science \& Biometrics Division, AFBI, Newforge Lane, Belfast, BT9 $5 P X, U K$

E-mail: louise.cooke@afbini.gov.uk

Late blight may cause total loss of organic potato crops in Northern Ireland. Cultivars with partial blight resistance previously withstood high infection pressure in trials, but the Phytophthora infestans population has recently changed. In 2008 and 2009, six cultivars were evaluated against current genotypes. These were, in both years, Santé and Sárpo Mira, with in 2008 Galactica and Setanta, and in 2009 Sunset and AFBI Loughgall clone L5937/2. Main plots (cultivars) were separated by unsprayed drills of cv. Désirée, inoculated with N. Ireland P. infestans isolates in 2008 and naturally infected in 2009. Treatments included no fungicide and a programme based on fluazinam (150 g a.i./ha, 'Shirlan', Syngenta) applied at extended intervals (4 and 2 applications in 2008 and 2009, respectively). In both years, foliage infection built up rapidly. In 2008, unsprayed Santé and Galactica were almost dead by 8 August, Setanta survived a week longer, but Mira had only $23 \%$ infection at the final assessment (29 August). Fluazinam delayed blight development; build up was slower in Setanta than in Santé and Galactica, but all were dead by 29 August while Mira had only 2\% infection. Mira had the greatest yield of healthy tubers for both untreated and fluazinam-treated plots. In 2009, Mira again developed less foliage blight than any other cultivar $(12 \%$ and $6 \%$, in untreated and fluazinam-treated plots respectively, at the final assessment, 4 September). Foliar infection was slower to build up in Sunset and L5937/2 than in Santé, but the untreated plots of all three were dead by the final assessment, while the fluazinam-treated plots had 47, 59 and 91\% infection, respectively. Yields were much lower than in 2008 and very poor in the untreated Santé, Sunset and L5937/ 2. Sunset and L5937/2 responded well to fluazinam; Mira gave a good yield even when unsprayed. Despite the presence of $P$. infestans genotypes including 'blue 13' A2, in both years Mira proved very resistant to foliage blight. Santé and Galactica proved too susceptible to be grown without fungicide; inputs may be reduced with Setanta and possibly also Sunset and L5937/2. 


\section{The Importance of Phytosanitary Controls for Sustainable Potato Production}

\section{L.E. Christoffersen}

European Commission, Food and Veterinary Office, Section for Plant Health and GMOs, Grange, Dunsany, Co. Meath, Ireland

E-mail: Lars.Christoffersen@ec.europa.eu

Movement of people and goods, globally and within the EU is constantly increasing making phytosanitary controls to prevent entry and spread of harmful organisms more important than ever. All EU Member States implement a common plant quarantine regime. The main legislative framework is Council Directive 2000/29/EC "on protective measures against the introduction into the Community of organisms harmful to plants or plant products and against their spread within the Community". The annexes to this directive list the organisms of particular concern, including some 34 named species or genera of relevance for potato. They also list conditions for, or bans on, imports into the EU of certain commodities; e.g. all imports of tuber/stolon forming species or hybrids of Solanum material, intended for planting, are forbidden. Member States can grant exceptions to the general requirements on a case by case basis for trial, varietal selection or scientific purposes, under strict official control, as laid down in Commission Directive 2008/61/EC. Member States are obliged to address new and emerging risks and notify the European Commission and the other Member States thereof. Those of more serious and general nature are then taken up in the European Standing Committee on Plant Health and the legal framework will, as necessary, be amended to address the risk, either by issuance of emergency measures, which is the quickest, or by a more permanent change of the annexes to the main directive. Risk assessments by Member States, by a working group under the Committee or by the European Food Safety Authority will generally have been done as part of the process. Member States' implementation of the common regime is monitored by the Commission, e.g. by inspections by the Food and Veterinary Office.

\section{Emerging Nematode Threats}

\section{C.C. Fleming}

Agri-Food and Biosciences Institute, Newforge Lane, Belfast, BT9 5PX, UK

E-mail: colin.fleming@afbini.gov.uk

Nematode problems in potato appear to be increasing in north-western Europe, with more frequent occurrences of damage caused by lesion nematodes (Pratylenchus), needle nematodes (Longidorus) and stubby root nematodes (Trichodorus and Paratrichodorus). Of most concern has been the emergence of root knot nematodes (Meloidogyne) as significant European potato pests, especially a new species, Meloidogyne minor. Since its discovery in the year 2000 on a potato crop in the Netherlands, M. minor has become a major problem on soccer pitches and golf courses, particularly in Ireland and Britain. Sampling of natural grassland has shown this species to be much more common than expected in Europe, and its spread into the amenity turfgrass sector appears to be a response to climate change and turf management practices. Early studies of the pest indicated that further damage to the European potato industry was likely in the future 
and during $2007 \mathrm{M}$. minor was found causing damage to potato crops in Ireland. Investigation of this recent outbreak has given a better indication of the potential threat from this new pest and here data are presented on the pathology of M. minor attack and the possible factors driving its spread into the agriculture sector.

\title{
New Variants of Dickeya and Pectobacterium Cause Increasing Problems with Potato Blackleg
}

\author{
J.M. van der Wolf ${ }^{1}$, R. Czajkowski ${ }^{1,2}$, K. Kristelijn ${ }^{3}$, H. Velvis ${ }^{3}$ and D. Boomsma ${ }^{3}$ \\ ${ }^{1}$ Plant Research International, Wageningen, the Netherlands \\ ${ }^{2}$ NIOO, Heteren, The Netherlands \\ ${ }^{3}$ HZPC, Metzlawier, The Netherlands \\ E-mail: Jan.vanderWolf@wur.nl
}

Blackleg pathogens belonging to Dickeya and Pectobacterium species are causing currently major economic damage in seed potato production in Europe. There are indications that the increasing problems are related to the occurrence of new variants of these pathogens. Since 2000, a genetic clade of Dickeya spp. unclassified strains are found, tentatively called "Dickeya solani", that increases in importance and replaces $D$. dianthicola in seed potatoes in Europe. D. solani has a broad host range, rapidly colonizes the potato root system, can be translocated via the vascular system from stems into progeny tubers, and is relatively resistant to microbial metabolites in comparison to $D$. dianthicola. Upon co-inoculation via vacuum-infiltration, $D$. solani outcompetes $D$. dianthicola. However, in field experiments in the Netherlands, the disease incidence caused by $D$. solani was on average as high as of $D$. dianthicola, although a large variation in results was found dependent on strains and seasons. Dickeya sp. does not survive for long free in soil. Minitubers are free of Dickeya and Pectobacterium, but infections are found already in the second year of seed multiplication. The bacteria may be introduced and spread via contaminated machines used during cultivation, haulm destruction, harvesting and grading. Soil-borne bacteria released from rotten tubers and translocated via free soil water to neighbouring plants may also contribute to the spread of the disease. Other concerns are the identification of a group of Pectobacterium carotovorum subsp. carotovorum strains that are able to cause blackleg and the recent finding of new Pectobacterium (sub)species, such as Pectobacterium wasabiae and Pectobacterium carotovorum subsp. brasilienses in other parts of the world.

\section{Monitoring Dickeya spp. in Potato Seed Tubers and the Association Between Seed Infection and Disease Incidence in the Field Under Warm Climate Conditions}

L. Tsror (Lahkim) ${ }^{1}$, O. Erlich ${ }^{1}$, S. Lebiush ${ }^{1}$, B. ben-Daniel ${ }^{1}$ and U. Zig ${ }^{2}$

${ }^{1}$ Agricultural Research Organization, Gilat Research Center, MP Negev, 85280, Israel

${ }^{2}$ Mao'n Enterprises Ltd., Israel

Email: tsror@agri.gov.il

Wilting and blackleg of potato in Israel, caused by Dickeya spp., was observed on crops of various cultivars grown from seed tubers imported from Northern 
Europe during the spring seasons of 2006-2010, with disease incidence of $0.2-$ $30 \%$. In addition to typical wilting symptoms on the foliage, in cases of severe infection, progeny tubers were rotten in the soil. The warm climatic conditions, during the growing season favour disease expression, and may result in the establishment of the pathogen in the potato ecosystem and a spread to weeds and other crops.

A protocol for detecting Dickeya latent infections in seed tubers has been developed using enrichment ELISA or bio-PCR. Its reliability was tested by following up the disease incidence in the field. Seed tubers sampled from commercial lots originating from The Netherlands, France, Germany and Scotland, were tested for latent infection. Out of 180 lots from The Netherlands 93 were positive, 6 out of 20 lots from Germany were positive, 2 out of 37 lots from France were positive and all 44 lots from Scotland were negative to Dickeya infection.

\title{
Population Dynamics of Streptomyces Species in Relation to Common Scab Incidence and Severity in Potato Crops
}

\author{
J.G. Elphinstone ${ }^{1}$, M. Stalham ${ }^{2}$, S.J. Wale ${ }^{3}$ and R. Thwaites ${ }^{1}$ \\ ${ }^{1}$ Food and Environment Research Agency, Sand Hutton, York, UK \\ ${ }^{2}$ Cambridge University Farm, Huntingdon Road, Cambridge, UK \\ ${ }^{3}$ Scottish Agricultural College, Craibstone Estate, Aberdeen, UK \\ Email: john.elphinstone@fera.gsi.gov.uk
}

A number of Streptomyces species, in addition to Streptomyces scabiei, were suspected to be causal agents of common scab in commercial fields in England and Scotland. Two of these, $S$. acidiscabies and S. turgidiscabies were confirmed as new records for the UK. These species appeared to be widespread in commercial production and were often detected on the same tuber and in the same common scab lesions. Quantitative real-time PCR assays were used to study population dynamics of pathogenic and non-pathogenic actinomycetes in commercial crops. Common scab development was related to the build up of pathogenic Streptomyces spp. on initiating tubers. Common scab levels varied from field to field and were inversely related to the total actinomycete activity of the soil during tuber initiation. The role of seed-borne Streptomyces in common scab development was confirmed to be minor in comparison with that of soil-borne inoculum, although the role of seed in spreading new pathogen species was expected to be important. Suppression of pathogenic Streptomyces populations in response to irrigation was evident in field trials, even under high pathogen inoculum pressure. Irrigation slowed the increase in pathogenic Streptomyces spp. between 1 and 3 weeks after tuber initiation compared with unirrigated plots. Pyrosequencing studies, on population dynamics of whole bacterial microflora on initiating tubers, raised the possibility that scab suppression by irrigation may be enacted at least partially by microbial taxa other than nonpathogenic actinomycetes. The largest increase in proportion of a single taxon in response to irrigation was observed in the genus Pseudomonas, levels of which were approximately $10 \%$ of the sequences identified to genus in irrigated plots but less than $2 \%$ in un-irrigated plots. 


\title{
Field Survey and Monitoring of Dickeya and Pectobacterium spp. in Northern Ireland
}

\author{
G.K. Young, C.C. Fleming, B.P.M. Moreland and R.E. Swan \\ Agri-Food and Biosciences Institute, Newforge Lane, Belfast, BT9 5PX, UK \\ E-mail: gillian.young@afbini.gov.uk
}

A new bacterial pathogen, provisionally named Dickeya solani, has recently emerged as a major threat to potato production in Northern Europe and Israel. The symptoms of this new strain are similar to those of the previously most common blackleg- and soft rot-causing bacterial species, Pectobacterium atrosepticum. However, D. solani seems to be more aggressive and has the potential to displace other bacterial species and become a major problem where introduced. A 3-year monitoring programme has recently begun to characterize blackleg- and soft rotcausing bacteria in Northern Ireland. This programme will primarily target potatoes imported for processing and as seed, but will also include a range of tuber and stem samples of home origin, as well as water samples from irrigation supplies and processing plants. Sixty samples have been characterized to date from a summer field survey of stems infected with blackleg-causing bacteria, but no Dickeya species have yet been identified.

\section{Fusarium graminearum as a Potato Dry Rot Pathogen}

\author{
G.A. Secor, V.V. Rivera, R. Estrada, R.R. Burlakoti and J.A. Delgado \\ Department of Plant Pathology, North Dakota State University, Fargo, ND, USA \\ E-mail: gary.secor@ndsu.edu
}

The known host range of $F$. graminearum $(F g$ ) has expanded to several non-cereal crops in the upper Midwest of the US, including potato, and $\mathrm{Fg}$ has been identified as a cause of potato dry rot in commercial stores. No significant differences in aggressiveness were found among isolates of $\mathrm{Fg}$ from potato, wheat and sugar beet regardless of original host. Fg requires larger wounds for infection of tubers compared to $F$. sambucinum, and a change in harvest practices may be a factor affecting the onset of dry rot caused by $F g$. Populations of $F g$ sampled from barley, wheat, potato, and sugar beet were tested to determine if they were a mixture of species or clades. Sequence analysis of two genes confirmed that populations were in the same clade of $F g$. Variable number of tandem repeat markers were used to determine the genetic structure of $\mathrm{Fg}$ from the four crop populations. Overall the results of these tests suggest that the populations are a single large population of $\mathrm{Fg}$ affecting these crops in our region. Tubers inoculated with $\mathrm{Fg}$ isolates from potato, sugar beet, and wheat and incubated at $10-12{ }^{\circ} \mathrm{C}$ for 5 weeks accumulated DON only in rotted potato tissue up to $39.68 \mu \mathrm{g} / \mathrm{ml}$, and NIV up to $18.28 \mu \mathrm{g} / \mathrm{ml}$. Tubers were inoculated with isolates of $F g$ chemotype DON and incubated for 7 weeks at $10-12{ }^{\circ} \mathrm{C}$ and assayed for DON diffusion into surrounding healthy appearing tissue. $\mathrm{Fg}$ was recovered from $53 \%$ of the inoculated tubers three $\mathrm{cm}$ distal to the rotted tissue, but DON was not detected in the surrounding tissue. Accumulation of trichothecenes in the asymptomatic tissue surrounding dry rot lesions caused by $F g$ is minimal in potato tubers stored for 7 weeks at processing store temperature. 


\title{
Alternaria and Alternaria-Like Lesions on Potato Crops in the Netherlands in 2009
}

\author{
L.J. Turkensteen and J. Spoelder \\ Hilbrands Laboratory for Soil Diseases (HLB), Wijster, The Netherlands \\ E-mail: j.spoelder@hlbbv.nl
}

From June to September 18, 2009, a survey was made of early blight leaf spots on potato leaflets in The Netherlands. Early blight leaf spots are marked by concentric rings and a dark brown colour. Leaflets with lesions were sampled and sent to HLB. These lesions were examined microscopically and through culturing for the presence of the three fungi Alternaria solani, A. alternata and Cladosporium cladosporioides, organisms which are considered as pathogenic, weakly pathogenic and nonpathogenic to potato foliage, respectively.

In addition other sporulating fungi were scored. In total, 112 samples were obtained yielding 768 lesions. It was found that 97 lesions were void of any of the three target organisms, 549 were free of $A$. solani and 248 lesions were free of both A. solani and A. alternata. Therefore, many lesions indistinguishable from true early blight did not carry any Alternaria species. Further it was found that A. solani showed up late during the growing season. The first sample carrying $A$. solani came in on July 21 and more than $50 \%$ of all samples with $A$. solani were collected in the period September 4 to 18 . From these results it is to be concluded that throughout the growing season of 2009, A. solani was not the main cause of Alternaria-like lesions, creating confusion among growers regarding crop protection. Similar results were obtained in 2010, with once again many Alternaria-like lesions being void of Alternaria solani.

It was shown that several nutrient deficiencies and excesses can cause the formation of lesions which may be mistaken for early blight. Most notable of these is boron deficiency, which leads to an increased susceptibility to damage by ozone and other radical molecules. A proper nutrient supply and soil structure before planting will avoid most of the problems with Alternaria-like lesions.

\section{Sensitivity of Alternaria solani Populations in Idaho to Commonly Used Fungicides and its Effect on Potato Early Blight Management in Idaho}

\author{
A.R. Belcher, E.M. Wood and P.S. Wharton \\ Department of Plant, Soil and Entomological Sciences, University of Idaho, \\ Aberdeen, ID 83210, USA \\ E-mail: pwharton@uidaho.edu
}

Early blight, caused by the fungus Alternaria solani, is an important disease on potato in Idaho. The strobilurin (QoI) fungicides (e.g. azoxystrobin and pyraclostrobin) are currently favoured as effective and safe methods for the control of early blight. QoI fungicides were registered for use on potato in the U.S. in the late 1990s. Soon after, in the early $2000 \mathrm{~s}$, isolates of $A$. solani with reduced sensitivity to the QoIs were detected across the Midwest. In 2007 and 2008 many Idaho potato growers reported the failure of these fungicides to control early blight. Thus, the goal 
of this project was to assess the prevalence of $A$. solani isolates with reduced sensitivity to the QoI fungicides in south-eastern Idaho. In 2009, 65 isolates were collected from leaves and tubers of potatoes grown in experimental and commercial fields. The isolates were tested for sensitivity to azoxystrobin, pyraclostrobin, famoxodone plus cymoxanil, and boscalid. Fungicide solutions were applied to potato dextrose agar (PDA) in a 2.5-log dilution in a continuous radial concentration gradient using a spiral plater. Fungal inoculum was placed in radial lines across the gradient. Fungicide sensitivity was expressed as an $\mathrm{EC}_{50}$, the fungicide concentration at which a fungal isolate's radial growth was equal to $50 \%$ of the average growth of the isolate on non-amended PDA. The results showed that all isolates tested (39) were highly resistant to azoxystrobin, but sensitive to pyraclostrobin. Three isolates out of twenty tested were found to be highly resistant to boscalid. This is the first report of boscalid insensitivity in A. solani.

\title{
Genetic Diversity and Population Biology of Colletotrichum coccodes in the United States Using Amplified Fragment Length Polymorphism Analysis
}

\author{
K.M. Alananbeh, J.S. Pasche and N.C. Gudmestad \\ Department of Plant Pathology, North Dakota State University, Fargo, ND 58102, \\ USA
}

Email: Neil.gudmestad@ndsu.edu

Black dot disease of potato, caused by Colletotrichum coccodes (Wallr.) Hughes, is widely distributed in the United States. However, little is known regarding the population biology of this fungus. A total of 366 single spore isolates of $C$. coccodes from nine states and 33 tester strains representing the seven vegetative compatibility groups of $C$. coccodes were analysed using Amplified Fragment Length Polymorphism (AFLP) markers. C. coccodes isolates recovered from potato plants were assigned to four NA-VCGs, NA-VCG1, NA-VCG2, NA-VCG4/5, and NA-VCG6/7. No isolates tested belonged to NA-VCG3. A total of 36 isolates formed distinct subclusters and could not be clustered with any NA-VCG. However, further analysis showed that these isolates were more related to NA-VCG1 than to any other NAVCG recovered. The United States $C$. coccodes population structure was confirmed with a high differentiation value $\left(G_{\mathrm{ST}}=0.46\right)$ among NA-VCGs. NA-VCG2 was the dominant group in the population $(n=238)$ and was the most frequent NA-VCG among states, fields, farms, and plants. However, in several instances there was more than one NA-VCG recovered from the same plant, field, farm, and state, indicating variability within the $C$. coccodes population in United States. A geographic pattern was observed for isolates originating from TX, MT, ND, and WI. Diversity within populations (states) and among populations accounted for $73 \%$ and $27 \%$ respectively. The genetic differentiation among the nine states was 0.33 and the overall gene flow was $N_{\mathrm{m}}=1.01$. These results suggest that several NA-VCGs are widely distributed in the United States and that they form a single large population of $C$. coccodes. AFLP markers were effective in evaluating the $C$. coccodes isolates in a relatively short period of time. However, using more primer pairs and other codominant markers such as simple sequence repeats could give another view about the genetic diversity of this fungus. 


\section{Blemish Diseases on Potato-Inoculum Source, Importance and Control}

L. Tsror (Lahkim) ${ }^{1}$, O. Erlich ${ }^{1}$, M. Hazanovsky ${ }^{1}$, S. Lebiush ${ }^{1}$, M. Aharon ${ }^{1}$, and U. $\mathrm{Zig}^{2}$

${ }^{1}$ Agricultural Research Organization, Gilat Research Center, MP Negev, 85280, Israel

${ }^{2}$ Mao'n Enterprises Ltd., Israel

Email: tsror@agri.gov.il

Potato blemish disease complex caused primarily by Helminthosporium solani, Colletotrichum coccodes, Rhizoctonia solani, and Spongospora subterranea is characterized either by scurfy-silvery patches on the tuber skin, sclerotia, or lesions which reduce the value of seed potatoes and production potential, and cause re-infection of daughter tubers grown from infected seeds. The damage caused by this disease complex became a major problem in potato production in Israel over the past few years due to an increased demand for washed potatoes with a high-quality appearance.

Israel imports $25,000 \mathrm{Mg}$ of seed tubers each year from northern Europe, mainly from the Netherlands (49\%), and also from Scotland (34\%), France (11\%) and Germany (6\%). With the imported seed tubers, various seed-borne pathogens are imported as well, affecting both the spring yield (including seed tubers harvested early in spring and planted during the autumn and winter), and the winter yield. Furthermore, some of these seed-borne pathogens which are also soil-borne, establish in the soil and become a major problem which requires frequent soil fumigation or other treatments to reduce soil infestation. A survey done during the last decade indicate that $74 \%$ of the imported seed lots were infested with $R$. solani, $84 \%$ with $H$. solani, $48 \%$ with $C$. coccodes and $33 \%$ with $S$. subterranea.

Seed tuber, in-furrow or other soil treatments should be considered according to the levels of contaminations with all pathogens involved in the blemish disease complex. Knowing the health status of both inoculum sources (seed or soil-borne) is important in choosing the optimal methods and fungicides for controlling the diseases (seed tuber, in-furrow treatment and soil fumigation).

\section{Real-Time PCR, A Risk Management Tool for Skin Spot in Potato}

G. Harper ${ }^{1}$, G.P. Stroud ${ }^{1}$, J.W. Woodhall ${ }^{2}$ and J.C. Peters ${ }^{2}$

${ }^{1}$ Potato Council, Sutton Bridge Crop Storage Research, Sutton Bridge, Spalding PE12 9YD, UK

${ }^{2}$ The Food and Environment Research Agency, Sand Hutton, York, YO41 1LZ, UK E-mail: gharper@potato.org.uk

Stocks of seed and ware tubers were tested at harvest for levels of Polyscytalum pustulans (skin spot) DNA using real-time PCR. Tested stocks were stored for 20 weeks under conditions conducive for skin spot development and the disease incidence and severity assessed. Large differences in skin spot development, and pathogen DNA levels, between individual cultivars were found. A general effect of harvest date was found in which later harvested crops had both higher levels of $P$. pustulans DNA at harvest and skin spot symptoms after storage than earlier harvested crops. The capability of a molecular diagnostic test to predict stocks most 
at risk of developing skin spot during storage was tested. The results for one season demonstrated the potential of the real-time PCR as a skin spot risk management tool although further validation is required.

\title{
Effect of Rhizoctonia solani Inoculum from Soil and from Seed Tubers on the Quality of Harvested Tubers: Controlling Disease by Seed and Soil Treatment
}

\author{
L. Dubois ${ }^{1}$, S. Szilvasi ${ }^{1}$ and S. Duvauchelle ${ }^{2}$ \\ ${ }^{1}$ Service of Alimentation (Plant Protection Service) Nord-Pas-de-Calais, France \\ ${ }^{2}$ Laboratory of Phytopathology de Loos-en-Gohelle (ipl, sustainable health and \\ environment), France \\ E-mail: ludovic.dubois@agriculture.gouv.fr
}

The severity of black scurf, caused by Rhizoctonia solani, on harvested tubers is related to weather conditions in the spring, but also to the level of inoculum in the soil and on the seed tubers. Trials to control black scurf were set up by the Plant Protection Service of the North of France between 2004 and 2008. The target of these trials was to determine the efficiency of fungicides in controlling both the inoculum on the tuber and the inoculum in the soil. Various application techniques were used. Ultra low volume sprays were used to compare fungicides applied to seed tubers. To combat Rhizoctonia solani in the soil, localised applications in the planting ridges were compared with applications over the whole surface of the plot. Various registered fungicides and new molecules were tested. The trials were set up within the same field, but one in a part with soil "free" of inoculum and a second in a part considered to be "contaminated".

For the "localised treatments", a planter with two spray nozzles was used. The treatment was made across a $30 \mathrm{~cm}$ width using a water volume of $801 \mathrm{ha}^{-1}$, with the first spray at ridge opening and the second one when the ridge was closed. The treatments over the whole surface were made in a volume of $300 \mathrm{l} \mathrm{ha}^{-1}$ with soil incorporation after the spray before the ridges were closed.

The results showed the impact of soil contamination on the quality of harvested tubers. When healthy seed tubers were planted in contaminated soil, $100 \%$ of the harvested tubers had black scurf. Inoculum on the seed tubers planted in inoculumfree soil also resulted in symptoms on harvested tubers. When the soil was only weakly contaminated with inoculum, the treatments in the ridge proved effective, but with severe contamination, applying the spray to the whole soil surface gave a better result. In soil free of inoculum, the seed treatments gave good results particularly on emergence.

\section{Spatial Distribution of Soil-Borne Pathogens to Inform Disease Risk Prediction}

\author{
J.C. Peters ${ }^{1}$, J.W. Woodhall ${ }^{1}$, J.L. Brierley ${ }^{2}$, S.J. Wale ${ }^{3}$ and A.K. Lees ${ }^{2}$ \\ ${ }^{1}$ Food and Environment Research Agency, Sand Hutton, York, YO41 1LZ, UK \\ ${ }^{2}$ Scottish Crop Research Institute, Invergowrie, Dundee, DD2 5DA, UK \\ ${ }^{3}$ SAC, Ferguson Building, Craibstone Estate, Aberdeen, AB21 9YA, UK \\ E-mail: jeff.peters@fera.gsi.gov.uk
}


Robust quantitative molecular diagnostic tools and soil DNA extraction techniques have recently been developed that enable detection and quantification of soil-borne inoculum for target pathogens such as Colletotrichum coccodes (black dot) and Rhizoctonia solani AG3 (stem canker and black scurf). These tests should allow the relationship between levels of soil inoculum and disease to be determined. However, advances in linking molecular diagnostics to disease epidemiology have been slow to develop. For diagnostic tools to be effective in predicting risk of disease, it is essential that we understand how soil-borne pathogens are distributed in soils. Fields with histories of $R$. solani and $C$. coccodes were intensively sampled by collecting 100 soil cores within a 4-ha area. The soil samples were individually tested by quantitative PCR. Contour plots of Kriged estimates for levels of $R$. solani AG3 DNA showed that there was one main cluster of inoculum stretching across the length of the sampled area. An analysis of the Ripley's K-function, a measure of the degree to which inoculum is aggregated, showed that inoculum was highly aggregated for samples collected 90 to $140 \mathrm{~m}$ apart $(P<0.05)$. This represents an area of approximately 2 to 3 ha. Analysis of $C$. coccodes distribution data indicates that this pathogen is more evenly distributed in soil than $R$. solani AG3. The data presented here support the current sampling strategy of 100 cores from a 4 ha area for the detection and quantification of soil-borne fungal pathogens.

\title{
Flea Beetles in Portugal, Damages on Potato Tubers: Old or New Enemies? New Threats for Sure!
}

\author{
J.F. Germain ${ }^{1}$, R. Oliveira ${ }^{2}$ and C. Chatot $^{2}$ \\ ${ }^{1}$ LNPV-Station d'Entomologie, CBGP Campus international de Baillarguet, 34988 \\ Montferrier-sur-Lez, France \\ ${ }^{2}$ Germicopa, 1 allée Loeiz Herrieu, 29334 Quimper, France \\ E-mail: catherine.chatot@germicopa.fr
}

Until 2004, no one had ever reported any potato tuber damage due to flea beetles (Alticinae) in North European potato production areas. However, in the vicinity of Porto (Portugal), potato tuber damage of unknown cause was observed at harvest since 2004 and for the next consecutive years with a southward natural spread. Only in 2008, identification of the putative damaging pest has been possible: flea beetles belonging to the Epitrix genus (Family Alticinae). Thorough field observations (potato foliage and tuber) were carried out and insect specimen collected. A complete review of systematic entomology was necessary to finally identify E. cucumeris (Harris) and E. similaris Gentner among the collected samples. Further research needs to be carried out to verify Koch's postulates and assess economical and technical consequences so that efficient control measures may be established without further delay.

\section{Development of Diagnostic Genetic Markers for Resistance to Globodera pallida in Cultivated Potato}

D. Griffin ${ }^{1}$, C. Moloney ${ }^{1}$, E. Dalton ${ }^{1}$, G. Bryan ${ }^{2}$, K. McLean ${ }^{2}$, J. Bradshaw ${ }^{2}$, I. Nagy ${ }^{1}$, M. Destefanis ${ }^{1}$ and D. Milbourne ${ }^{1}$

${ }^{1}$ Crops Research Centre, Teagasc, Oak Park, Carlow, Ireland 
${ }^{2}$ Genetics Programme, Scottish Crop Research Institute, Invergowrie, Dundee, DD2 $5 D A, U K$

Email: Denis.Griffin@teagasc.ie

Complete sequence-based characterisation of resistance gene loci offers a route for the development of diagnostic markers and haplotypes for use in resistance breeding. We are currently in the process of characterising the major disease resistance locus on potato chromosome 4 in the two genotypes (RH and DM) that are the basis for the potato genome sequencing initiative. Our earliest efforts to demonstrate the utility of this sequence information for breeding have revolved around a large effect quantitative trait locus (QTL) on linkage group IV $\left(G_{p a I V}{ }_{a d g}{ }^{s}\right)$ conferring resistance to G. pallida pathotype Pa2/3. The QTL was originally mapped in the tetraploid breeding line $12601 \mathrm{ab} 1$. We have shown that GpaIV $_{\text {adg }}{ }^{s}$ is also present in a breeding line called C1992/31 via genetic mapping in an F1 population produced by crossing C1992/ 31 with the cultivar Record. C1992/ 31 is relatively divergent from $12601 \mathrm{ab1}$, confirming that $\mathrm{GpaIV}_{a d g}{ }^{s}$ is an ideal target for marker-assisted selection in currently available germplasm. To generate markers exhibiting diagnostic potential for $\mathrm{GpaIV}_{a d g}{ }^{s}$ sequences from several bacterial artificial chromosome (BAC) clones from the resistance gene region were exploited to develop multiple primer sets generating single-copy amplicons, which were examined for polymorphisms exhibiting linkage to $\mathrm{GpaIV}_{a d g}{ }^{s}$ in $\mathrm{C} 1992 / 31$. Eight such polymorphisms were found. Testing and validation in two panels of potato germplasm of direct relevance to commercial potato breeding programmes allowed the identification of four markers (one In/Del and three single nucleotide polymorphisms). Using these markers and others (derived from the available literature), we are now considering how best to practically implement marker assisted selection for resistance in a commercial potato breeding programme.

\title{
Occurrence of Stem Blight Caused by Latent Infections of Seed Tubers with Phytophthora infestans (Mont.) de Bary
}

\author{
S. Keil, M. Benker and M. Zellner \\ Bavarian State Research Centre for Agriculture, Freising, Germany \\ E-mail: Michael.Zellner@LfL.bayern.de
}

In potato cultivation, early stem blight leads to high late blight pressure and results in losses in quality and yield. The main cause of stem blight is the latent infestation of seed tubers with Phytophthora infestans. With high soil humidity the fungus expands into the stem or sporulates on the infested tuber and passes the disease on to neighbouring plants. For this reason we analysed certified seed potatoes from all over Europe in order to identify the rate of latent infestation present. From 2007 to 2009 a total of 17 batches were tested, five from organic and 12 from conventional production. Samples were prepared and DNA extracted. Using PCR diagnosis it was possible to show that latent infestation is a common phenomenon. Infection rates from $2 \%$ up to $38 \%$ were found while only 3 out of the 17 batches were free of $P$. infestans. The overall average 
infestation rate was $11 \%$. Comparing organically and conventionally produced seed tubers showed no significant differences (t-test, $P<0.05$ ). The given data illustrate that there is a considerable risk of bringing $P$. infestans into the field with seed tubers even when using certified and symptomless tubers. That is why control measures are highly recommended. Systemic products that spread into the plant tissue can reduce the growth of the fungus within the plant. In organic farming the treatment of seed tubers with copper is a possibility to reduce primary infections; however, the use of protective fungicides in conventional production proves to be more efficient. It is important to keep the infection rate as low as possible as they initiate new infections in the field the following year. In our further research we will therefore focus on establishing scientifically based methods to reduce the latent infection rate of $P$. infestans in potato seed tubers.

\title{
Development of Real Time Quantitative PCR Assays for Detection and Identification of Dickeya species Pathogenic to Potato
}

\author{
J.G. Elphinstone ${ }^{1}$, N.M. Parkinson ${ }^{1}$, V. Bertrand ${ }^{1}$, L. Pritchard ${ }^{2}$ and I.K. Toth ${ }^{2}$ \\ ${ }^{1}$ Food and Environment Research Agency, Sand Hutton, York, UK \\ ${ }^{2} S C R I$, Invergowrie, Dundee, UK \\ Email: john.elphinstone@fera.gsi.gov.uk
}

Reclassification of Erwinia chrysanthemi into six species of Dickeya and the emergence in the European potato trade of a potentially damaging new species (proposed as Dickeya 'solani') warranted development of diagnostics for rapid, accurate detection and discrimination of the various pathogens causing blackleg and soft rot of potato. In addition to Pectobacterium atrosepticum and Dickeya dianthicola, the latter of which has been spreading on potato in Europe for over 30 years, a number of other Dickeya species (including D. chrysanthemi, D. dadantii and D. zeae) have entered on ornamental hosts and are known as potato pathogens in other parts of the world. Whole genome sequences, previously obtained for 16 isolates of Dickeya species and strains, were compared by means of a bioinformatics analytical pipeline using the EMBOSS software packages ePrimer3 and primersearch, the CDS prediction package Prodigal, and NCBI BLAST. Unordered fragments from draft genome assemblies were used to predict potential primer sets, their corresponding amplicons and internal oligonucleotide probes, which were either strain-specific, species-specific or Dickeya-specific and which fulfilled the criteria required for use in real time PCR assays. Selected assays were validated against a panel of 72 Dickeya isolates representing the range of phylogenetic variation in the recA gene. A universal assay for detection of all Dickeya species and a further two assays for specific detection of $D$. 'solani' and $D$. dianthicola have so far been selected for further validation on extracts from artificially contaminated and naturally infected tubers and stems. Additional comparisons were made with previously designed real-time PCR assays with specificities suitable for detection of (a) all pectolytic Pectobacterium and Dickeya spp., (b) all Dickeya spp. and (c) Pectobacterium atrosepticum. 


\title{
Biofumigation for Controlling Streptomyces spp. and Rhizoctonia solani of Potatoes and Factors that Impact its Effectiveness
}

\author{
K. Bouchek-Mechiche ${ }^{1,2}$, B. Mille ${ }^{1}$ and F Montfort ${ }^{1}$ \\ ${ }^{1}$ UMR 1099 BiO3P INRA/ Agrocampus Rennes/Université Rennes 1, INRA/ BP \\ 35327, 35653 Le Rheu Cedex, France \\ ${ }^{2}$ GNIS, 44 Rue du Louvre, 75001 Paris, France \\ E-mail: karima.bouchek@rennes.inra.fr
}

The objective of this study was 1) to assess the biofumigant potential of Brassica juncea (brown mustard line 1420) on $R$. solani and Streptomyces spp. growth and 2) to determine biofumigation effectiveness according to soil inoculum density and crushed residues quantity incorporated into the soil, against potato scab and black scurf.

In vitro, $R$. solani and Streptomyces spp. sensitivity to volatile compounds from $B$. juncea was investigated using a Petri dish-container bioassay. Effects of residue incorporation rates $\left(50,25\right.$ and $0 \mathrm{~g}$ Fresh Crushed Residues FCR ${ }^{-1}$ of soil) and inoculum density ( 1 and $5 \% \mathrm{v} / \mathrm{v}$ ) were tested in the greenhouse.

In vitro, B. juncea was the most effective compared to other tested plants (rye, white mustard, radish and oats) in reducing bacterial and fungal growth. $R$. solani was completely (mycelium) or almost completely (sclerotia) inhibited by B. juncea volatiles; it seems to be more sensitive than Streptomyces species. The inhibition effect of B. juncea volatiles on Streptomyces spp. is related to bacterial concentrations. Streptomyces growth was only delayed at high concentration but completely inhibited at moderate and low bacterial concentration. The greenhouse experiment showed that the quantity of residues and inoculum density were significant factors for biofumigation effectiveness. Compared to control without residues, incorporating high amounts of residues $\left(50 \mathrm{~g} \mathrm{FCR}^{-1}\right.$ soil) reduced black scurf and stolon cankers incidence by 40 to $100 \%$ according to soil inoculum densities 5 and $1 \% \mathrm{v} / \mathrm{v}$, respectively. Half of the incorporated residues $\left(25 \mathrm{~g} \mathrm{FCR}^{-1}\right.$ of soil) led to inefficient biofumigation on $R$. solani. For Streptomyces spp., biofumigation significantly reduced scab on tubers and roots only when high

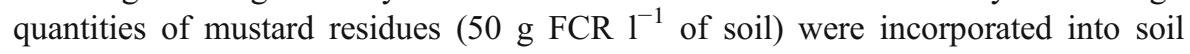
infested with low inoculum density ( $1 \%$ volume of inoculum/volume of soil).

\section{The Use of Natural Plant Volatile Compounds for the Control of the Potato Blemish Pathogens}

E.M. Wood, A.R. Belcher and P.S. Wharton

Department of Plant, Soil and Entomological Sciences, University of Idaho, Aberdeen, ID 83210, USA

E-mail: pwharton@uidaho.edu

Many naturally occurring plant volatiles are known for their antifungal properties. However, they have limited use because they diffuse rapidly after coming in contact with the atmosphere. In this study, 2E-hexenal was chosen as a prototype volatile in order to investigate the use of plant volatiles for the control of potato blemish pathogens in fresh-pack potato packaging. The two main 
potato blemish disease pathogens, Colletotrichum coccodes (black dot) and Helminthosporium solani (silver scurf) were used in the study. Cultures of the two pathogens, grown on potato dextrose agar were exposed to the pure volatiles in sealed mason jars for 7 days at $23{ }^{\circ} \mathrm{C}$. Radial fungal growth and the concentration of the volatile were measured daily and the concentration required to inhibit fungal growth was determined. The objectives of this study were to determine the optimal concentrations of plant volatiles required to inhibit fungal growth, and to determine whether the volatile is fungistatic and fungitoxic or both. Results showed that $2 \mathrm{E}-$ hexenal was highly toxic to all three test pathogens.

\section{Search for Molecular Markers Linked to the Late Blight Resistance of Potato Cultivar Sárpo Mira}

\section{Tomczyńska and J. Śliwka}

Plant Breeding and Acclimatization Institute, Młochów Research Centre, Poland E-mail: i.tomczynska@ihar.edu.pl

Late blight, economically the most important potato disease worldwide, is caused by the oomycete Phytophthora infestans. This pathogen was responsible for the Irish Potato Famine in the 19th century and also nowadays causes multibillion-euro losses annually in potato production. One of the important ways of late blight control is breeding new, highly resistant potato varieties. Sárpo Mira is a representative of the highest resistance class. Unfortunately, due to its agricultural traits, it has become popular only in organic agriculture and allotment gardens. The unknown pedigree of Sárpo Mira is also an impediment in its use in breeding programs.

Sárpo Mira was crossed with the susceptible variety Maris Piper by John Bradshaw and Alison Lees from SCRI, UK, who kindly shared the progeny with us. The inheritance of resistance was tested by detached leaf tests (with three P. infestans isolates: MP324, MP618 and MP650). The progeny segregated for resistance in two clear classes: highly resistant and susceptible. However, the presence of quantitative resistance was also observed. We plan to map the Sárpo Mira resistance using the candidate locus approach i.e. to test markers from well-established resistance hot spots for co-segregation with the phenotypic resistance in the Sárpo Mira $\times$ Maris Piper population. Such markers can later be useful in marker assisted selection of resistant individuals carrying Rpi-srpl.

\section{Selection of Potato Breeding Clones Resistant to Potato Nematode Globodera rostochiensis Ro1 Using Artificial Inoculation and Application of Molecular Marker Assisted Selection in State Priekuḷi Plant Breeding Institute, Latvia}

\section{G. Ūsele, I. Mežaka and I. Skrabule}

State Priekuļi Plant Breeding Institute, Latvia

E-mail: guna.usele@gmail.com

Potato cyst nematodes (PCN) are a major problem in worldwide potato production especially in cool-temperate areas. Breeding of resistant cultivars is the most desirable and effective method of control of this pest. Potato breeding 
material has been screened using artificial inoculation in the State Priekuli Plant Breeding Institute since the year 2000. Third year generation tubers have been planted in pots with soil infected with nematodes. The pathotype Rol of Globodera rostochiensis was used for inoculation, as it is the only confirmed pathotype present in Latvia. Inoculation was carried out in May and after 811 weeks the degree of infection was determined and clones susceptible to nematodes were discarded. The percentage of resistant breeding clones in the tested material varied each year from 64 to $71 \%$. Even if both parents were resistant to the nematode, no more than $80 \%$ of progeny was resistant therefore testing is especially significant because even use of resistant parents does not guarantee resistant progeny. Molecular markers for detection of nematode resistance genes have been used since 2010. Marker assisted selection (MAS) could speed up breeding work and save material and labour costs. Markers Ro1 (indicator of gene $H 1$ from S. tuberosum spp. andigena) and Grol (indicator of the presence of genetic material of $S$. spegazzinii), published by Biryukova, were used to detect resistance genes in breeding clones and simultaneously the same clones were artificially inoculated with nematodes to verify the results obtained with molecular markers.

\section{Incidence of Skin Blemish Diseases in Poland}

\section{J.S. Kapsa, E. Bernat, H. Gawińska-Urbanowicz, J. Osowski and S. Wójcik IHAR- PIB Radzików, Department of Potato Protection \& Seed Science in Bonin, Poland}

E-mail: jkapsa@wp.pl

Skin blemish diseases such as silver scurf (Helminthosporium solani), black scurf (Rhizoctonia solani) and common scab (Streptomyces spp.) have become increasingly important for seed potato production and also for ware growers who are supplying supermarkets with potatoes for the washed pre-packed market. In the years 2005-2007, 41 potato cultivars were evaluated for reaction to silver scurf, black scurf and common scab under field conditions through screening trials. Uninfected tubers, of three different maturity groups, were hand-planted in naturally infected soil. At harvest, four of $10-\mathrm{kg}$ samples per cultivar were dug. All tubers were washed, visually assessed for silver scurf, black scurf and common scab and graded into five categories: $0=$ healthy, $1<5 \%, 2=5.1-25 \%$, $3=25-50 \%$ and $5>50 \%$ surface area infected. A severity score for each cultivar was calculated as the severity index. The trials were repeated during three growing seasons. Severity of silver scurf significantly depended on season (year), maturity group and cultivar reaction. In natural (field) infection, tubers of cvs Felka, Kuklik, Krasa (early), Irga (mid-early) and Danusia (late) were more affected with silver scurf than the rest of the genotypes. Severity of black scurf varied insignificantly between seasons and potato maturity groups. Only a few cultivars were more affected with the disease in the year 2005 (Delikat, Molli, Bartek). Incidence of common scab significantly depended on seasons and maturity groups. The most affected with common scab were early cultivars (Collette, Bard, Felka and Orlik) in 2005. 


\title{
Phytophthora infestans in Ireland-An Evolving Pathogen
}

L.R. Cooke ${ }^{1}$, S. Kildea ${ }^{2}$, D. Griffin ${ }^{2}$ and K.L. Deahl ${ }^{3}$

${ }^{1}$ Agri-Food and Biosciences Institute, Newforge Lane, Belfast, BT9 5PX, UK

2 Teagasc Crops research Centre, Oak Park, Carlow, Ireland

${ }^{3}$ USDA, ARS, Vegetable Laboratory, Beltsville, MD-20705, USA

Email: louise.cooke@afbini.gov.uk

In Ireland, Phytophthora infestans is notorious as the cause of the potato 'murrain' now known as late blight. The extreme dependence of the population on a single crop, the potato, and the arrival in August 1845 of what was later shown to be a newly-introduced pathogen led to an unprecedented disaster: the Great Famine (An Gorta Mór). It is estimated that one and a half million people died and over a million emigrated from Ireland between 1845 and 1850: the impact of this continues to the present day.

The origin of $P$. infestans and the routes by which it reached Europe remain controversial. It is unclear whether the initial pathogen migrations of the $1840 \mathrm{~s}$ included both mating types, but by the mid- $20^{\text {th }}$ Century, outside Mexico, its worldwide population was dominated by a single clonal lineage of the A1 mating type (US-1). This changed after new strains of both mating types were introduced to Europe, probably via a shipment of potatoes from Mexico in 1976.

The A2 mating type was first identified in Northern Ireland in 1987 and in the Republic of Ireland the following year. By the mid-1990s, the first detailed molecular studies of the P. infestans population in Ireland found no trace of the old US-1 lineage; the population was dominated by new A1 strains (the new A2 types occurred only at a low frequency). The A2 mating type apparently failed to establish and was not detected after the mid-1990s until 2005, but in the last 4 years its frequency has increased dramatically. Fingerprinting of selected A2 isolates from Northern Ireland in 2007 showed that most belonged to the genotype 'Blue 13' (13_A2), which has dominated the population in Great Britain since 2006. By 2009, over $50 \%$ of isolates from extensive surveys throughout the island of Ireland proved to be A2; SSR analysis showed that these all belong to the Blue 13 clonal lineage. Once again potato blight in Ireland is on the move.

\section{The Current Japanese Population of Phytophthora infestans was Formed Through Migration from Other Countries and Domestic Mutation}

\author{
S. Akino ${ }^{1}$, S. Kildea ${ }^{2}$, N. Kondo ${ }^{1}$ and L.R. Cooke ${ }^{3}$ \\ ${ }^{1}$ Hokkaido University, Sapporo, Japan \\ 2 Teagasc Crops Research Centre, Oak Park, Carlow, Ireland \\ 3 AFBI, Belfast, UK \\ E-mail: sakino@res.agr.hokudai.ac.jp
}

Potato late blight was first reported in Japan in 1900. The existence of both the A1 and A2 mating types of Phytophthora infestans was confirmed in the 1980s. Since then, Japanese isolates have been classified as US-1, JP-1, JP-2, JP-3, and JP-4 using allozymes, mtDNA haplotypes, and RG57 fingerprints. The analysis indicated that 
US-1, JP-1, and JP-2 invaded Japan before the 1970s, 1980s, and 1990s, respectively. JP-3 is thought to be the progeny of mating between JP-1 and JP-2. A genotype identical to JP-2 was previously reported in continental China, Far Eastern and European Russia, continental Europe, Great Britain, and Ireland. Simple sequence repeat (SSR) analysis indicated that the Chinese genotype HeGan A1-A matched JP-2. Many alleles shared by JP-2 and Northern Irish NI-1 were identical, although there were differences at some loci. Japanese JP-2 was thought to have originated in Europe and invaded Japan, after which some mutations occurred. Although the Pi26 and G11 alleles of JP-4 were unusual compared with other Japanese groups, these alleles were found in Chinese CN-6 and Northern Irish NI-1. JP-4, also considered having a close genetic relationship with Chinese and European groups, invaded Japan around 2000. The current Japanese population of P. infestans likely formed via several migrations from other countries and domestic mutation. We consider it necessary to understand and control the path by which the epidemic has spread in Japan after considering its relationship with populations in other countries.

\section{Post-Harvest Development of Black Dot (Colletotrichum coccodes) on Potato}

G.P. Stroud ${ }^{1}$, G. Harper ${ }^{1}$, S.J. Wale ${ }^{2}$, A.K. Lees $^{3}$, J.L. Brierley ${ }^{3}$ and J.C. Peters ${ }^{4}$

${ }^{1}$ Sutton Bridge Crop Storage Research, AHDB Potato Council, Sutton Bridge, Spalding, PE12 9YD, England

2 SAC, Craibstone Estate, Aberdeen, AB21 9YA, Scotland

${ }^{3}$ Scottish Crop Research Institute, Invergowrie, Dundee, DD2 5DA, Scotland

${ }^{4}$ The Food and Environment Research Agency, Sand Hutton, York, YO41 1LZ, England

E-mail: gstroud@potato.org.uk

The skin blemish disease black dot caused by Colletotrichum coccodes can cause unacceptable appearance of potato tubers with subsequent rejection by customers. The greater requirement for blemish-free tubers has driven research into the factors that influence disease development from the seed through cultivation, harvest and storage. The earlier development of a real time PCR assay able to quantify $C$. coccodes DNA from tubers and in soil allowed some of these factors to be investigated. Two factors were significant for disease development, the time period between plant emergence and harvest and the immediate post-harvest treatment of tubers.

\section{Antioxidant Activity and its Relation to the Content of Phenolic Compounds in Seven Varieties of Potato}

J. Valcarcel ${ }^{1}$, K. Reilly ${ }^{1}$, M. Gaffney ${ }^{1}$, N. Brunton ${ }^{2}$ and N. O'Brien ${ }^{3}$

${ }^{1}$ Teagasc-Kinsealy Research Centre, Dublin, Ireland

${ }^{2}$ Teagasc-Ashtown Food Research Centre, Dublin, Ireland

${ }^{3}$ Department of Food and Nutritional Sciences, U.C.C., Cork, Ireland

E-mail: jesus.barros@teagasc.ie

Diets rich in fruits and vegetables have been associated with a decreased risk of atherosclerotic heart disease and certain cancers. It is believed that bioactive 
compounds present in these foods protect lipoproteins and DNA in part due to their antioxidant properties. Beneficial compounds include some vitamins and nonnutritional molecules present in all vegetable tissues known as phytochemicals. Potatoes are one of the most consumed vegetables and therefore an important source of these antioxidant compounds. The majority of phytochemicals found in potatoes are polyphenols, plant metabolites with a structure based on an aromatic ring with one or more hydroxyl substituents. They tend to be soluble in water and are easily extracted by alcoholic solutions. We evaluated the protective capabilities of methanolic solutions extracted from the skin and flesh of seven varieties of potato against the stable radical 2,2-diphenyl-1-picrylhydrazyl (DPPH) and analysed its relation to the content of total phenolics and total flavonoids using spectrometric methods.

\title{
State Collection of Phytophthora infestans (Mont.) de Bary Strains in the All- Russian Research Institute of Phytopathology and the Tasks, Performed by its Use
}

\author{
A.A. Makarov, V.P. Dubovoy, I.N. Kozlovskaya, and E.V. Morozova \\ All-Russian Research Institute of Phytopathology, Russian Academy of Agricultural \\ Sciences, Bolshie Vyazemy, Moscow region, 143050 Russia \\ E-mail: dybovoy@vniif.ru
}

The State Collection of Phytopathogenic Microorganisms, established on the basis of the All-Russian Research Institute of Phytopathology, includes 4,200 isolates of different pathogens, for breeding, phytopathological, genetic, and toxicological studies; among these, there are 480 isolates of Phytophthora infestans (Mont.) de Bary. The problems, solved via the use of our collection, include assisting breeders in creating new late blight resistant potato cultivars. To do this, a new method for the laboratory and field assessment of new potato cultivars for their nonspecific late blight resistance has been developed. The main point of this method, applied in the field nursery, is that during the full flowering stage, mid-layer leaves are collected and then tested under laboratory conditions for their resistance to a test set of 6-8 $P$. infestans pathotypes, stored in our collection and differing in their virulence, aggressiveness, mating type, and geographic origin. The basic assessment and selection criteria are the infection efficacy, necrotic lesion growth rate, and sporulation ability. The averaged laboratory assessment of potato cultivars for their nonspecific resistance is highly correlated with the results of field assessment. Studying the nonspecific resistance of plants, we have concluded that the growing of cultivars possessing such resistance, both stabilizes potato production and represents a highly efficient way to prevent or reduce consequences of possible bioterrorist acts in a plant breeding field.

Open Access This article is distributed under the terms of the Creative Commons Attribution Noncommercial License which permits any noncommercial use, distribution, and reproduction in any medium, provided the original author(s) and source are credited. 